\title{
Facial cutaneous metastasis of rectal adenocarcinoma
}

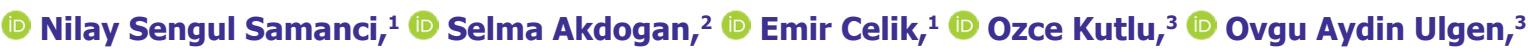 \\ D Fuat Hulusi Demirelli ${ }^{1}$ \\ ${ }^{1}$ Department of Medical Oncology, Istanbul University-Cerrahpasa, Cerrahpasa Faculty of Medicine, Istanbul, Turkey \\ 2Department of Internal Medicine, Istanbul University-Cerrahpasa, Cerrahpasa Faculty of Medicine, Istanbul, Turkey \\ ${ }^{3}$ Department of Patology, Istanbul University-Cerrahpasa, Cerrahpasa Faculty of Medicine, Istanbul, Turkey
}

\begin{abstract}
Skin metastasis caused by carcinomas is associated with poor prognosis and is a rare and late clinical finding. Skin metastases occur in only 4-6.5\% of Stage IV colorectal cancer. We present an unusual case of Stage IV unresectable rectal adenocarcinoma metastasized to the head and face. One and a half years after diagnosis, new skin lesions developed on his face. Biopsy showed mucinous adenocarcinoma consistent with rectal malignancy. Moreover, he died 3 months after the diagnosis of cutaneous metastasis. This case emphasizes the importance of the effect of skin lesions on prognosis in patients with a history of malignancy.

Keywords: Neoplasm metastasis; rectal neoplasms; scalp; skin.
\end{abstract}

Cite this article as: Sengul Samanci N, Akdogan S, Celik E, Kutlu O, Aydin Ulgen O, Demirelli FH. Facial cutaneous metastasis of rectal adenocarcinoma. North Clin Istanb 2021;8(5):518-520.

$\mathrm{C}$ olorectal cancer (CRC) is a globally important public health issue and it is the fourth most frequently diagnosed cancer. In fact, the incidence of CRC decreased at a rate of approximately $2.9 \%$ per year or greater between 2005 and 2014 [1]. By the time they are diagnosed, more than $10 \%$ of cases are already metastatic tumors. The sites most often affected by the advanced disease are the liver, lungs, and central nervous system. Skin metastases caused by abdominal malignancies are rare and occur in less than $5 \%$ of patients. Usually associated with poor prognosis. Skin metastasis of adenocarcinoma of the rectum is even rarer and occurs in less than $4 \%$ of patients. It is frequently found in the abdominal wall and umbilicus [2]. In this Case, we report a patient with metastatic rectum cancer with cutaneous metastasis of head and face.

\section{CASE REPORT}

A 45-year-old man admitted with rectal bleeding who was diagnosed with adenocarcinoma of the rectum. The patient underwent total body positron emission tomography-computed tomography (PET-CT) scan to restage the tumoral disease. The PET-CT test showed adrenal metastasis and lung metastasis. K-Ras and N-Ras were revealed as wild type and the palliative chemotherapy was started as 5-fluorouracil, leucovorin, oxaliplatin, and cetuximab 12 cycles. After 12 cycles, chemotherapy PET-CT showed new multiple mediastinal and hilar lymph nodes, a large tissue mass between kidney and spleen. The second line chemotherapy was used for progressed disease. 5-fluorouracil, leucovorin, irinotec-

Received: October 16, 2019 Accepted: January 07, 2020 Online: July 23, 2020

Correspondence: Nilay SENGUL SAMANCI, MD. Istanbul Universitesi, Cerrahpasa Tip Fakultesi, Tibbi Onkoloji Anabilim Dali, Istanbul, Turkey.

Tel: +902124143000 e-mail: nilaysengulsamanci@gmail.com

(c) Copyright 2021 by Istanbul Provincial Directorate of Health - Available online at www.northclinist.com 


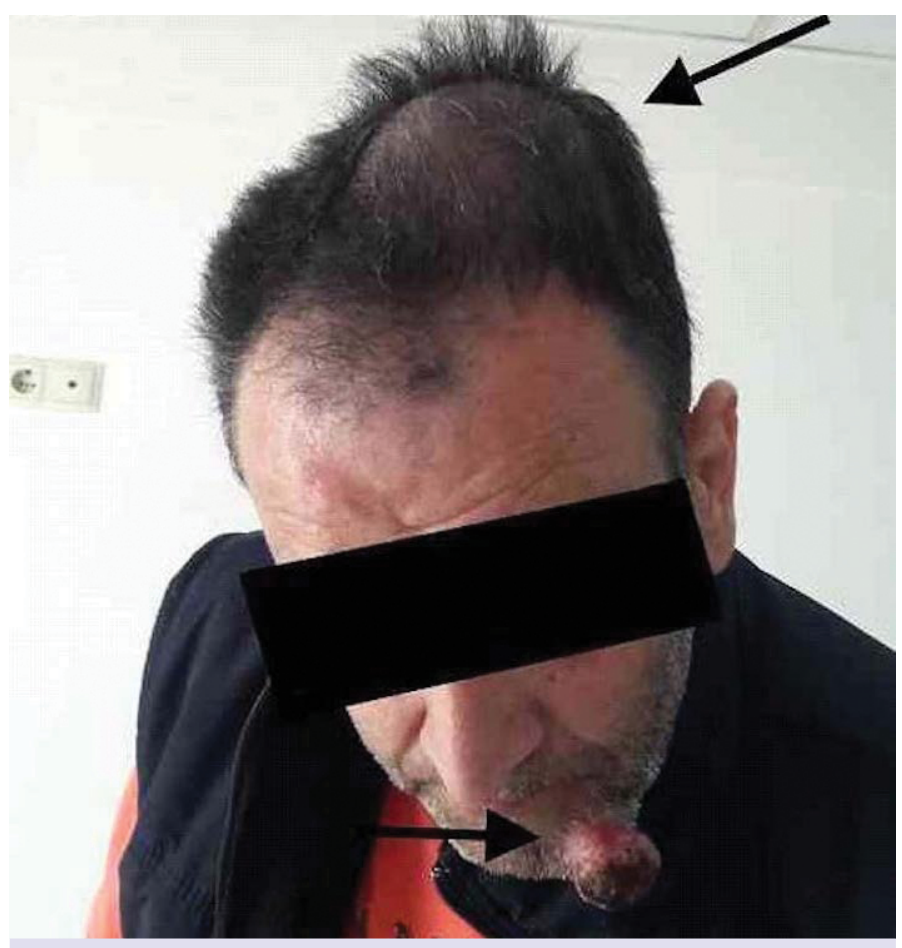

FIGURE 1. Subcutaneous lump was seen on his scalp and mandibular.

an, and bevacizumab were started. After 6 cycles of regimen, new lymph nodes appeared in his abdomen and his intra-abdominal mass become greater. His treatment changed to regorafenib $120 \mathrm{mg} /$ day. Five months later on his physical examination, a subcutaneous lump was seen on his scalp and mandibular (Fig. 1). Computerized tomography of the brain revealed a $13 \times 7.5 \mathrm{~cm}$ mass in the left parietal region that disrupted the calvarial bone (Fig. 2). A biopsy of the scalp lesion with a diameter of 0.5 $\mathrm{cm}$ was obtained. Histological examination of biopsied tissues showed metastasis of rectal adenocarcinoma (Fig. $3)$. His performance become worsening, he hospitalized and palliative support treatment was started. He died 3 months after the diagnosis of cutaneous metastasis.

\section{DISCUSSION}

The incidence of skin metastasis ranges from $0.7 \%$ to $10.4 \%$ of all cancer patients [3]. Only 3\% of CRCs spread to the skin. Facial lesions are extremely uncommon. Literature mentions only a few cases. Moreover, it should be differentiated from primary carcinoma of skin. Colorectal adenocarcinomas usually spread their metastases to the liver, peritoneum, pelvis, lung, and bone within the first 2 years after resection of the primary tumor [4]. Al-

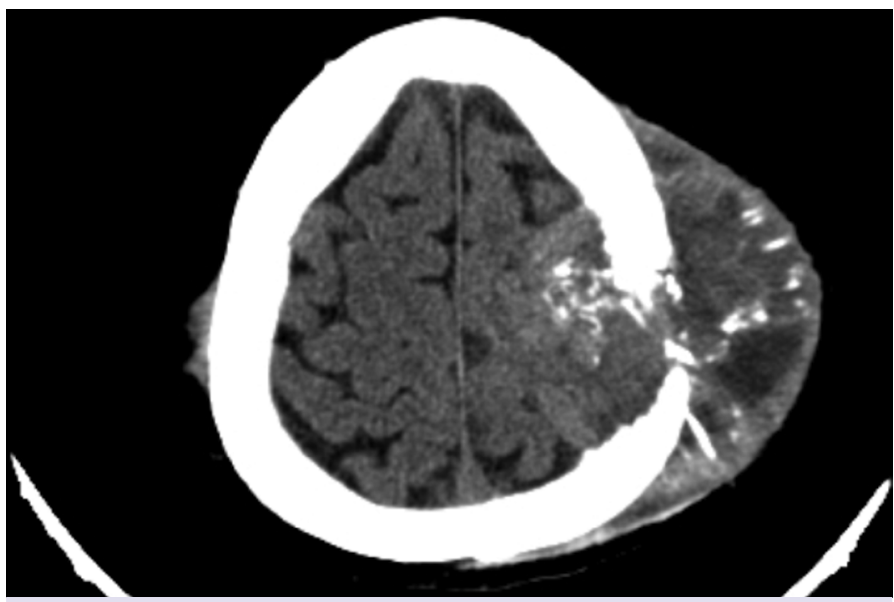

FIGURE 2. Brain computed tomography revealed a $13 \times 7.5$ $\mathrm{cm}$ mass which destructed calvarial bone in the left parietal region.
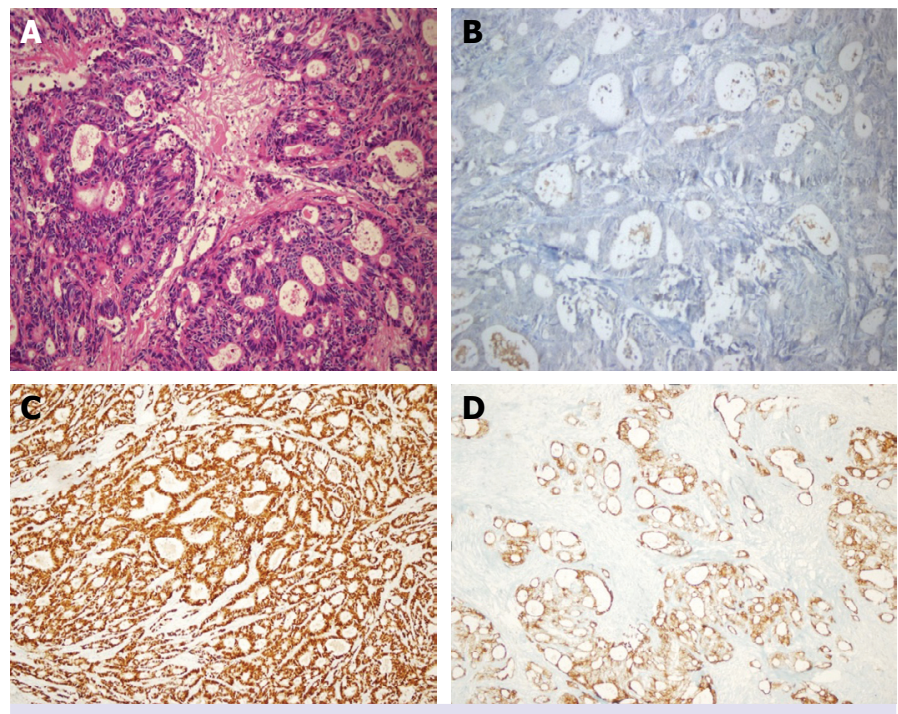

FIGURE 3. (A) Adenocarcinoma in cribriform pattern H\&E $\times 100$. (B) GCDFP-15 immune negativity in tumor cells $\times 100$. (C) CDX-2 immune positivity in tumor cells $\times 40$.

(D) CK-20 immune positivity in tumor cells $\times 40$.

though skin metastasis of adenocarcinoma of the rectum is more rare, the most common site of skin metastasis is the middle or lower dermis of the abdomen and the perianal skin. The pelvis, chest, back, upper extremities, head and neck, and rarely glans penis, face, and hand are the other skin sites of colorectal metastasis [5]. Cutaneous metastases clinically appear as a subcutaneous or intradermal nodule, a nodulocystic lesion, an ulceration, a cellulitis-like lesion, or fibrotic processes. In this case, it is occurred as a subcutaneous nodule and destroyed the bone. Biopsy is the gold standard diagnostic method for 
cutaneous metastasis. In this paper, the site of metastasis was on head and face and it is confirmed by biopsy.

Cutaneous metastases have been shown to be associated with poor prognosis [6]. Management of metastatic CRC including skin metastasis is based on systemic chemotherapy [7]. For isolated lesions, Nesseris et al. [8] suggested wide local excision, but systemic chemotherapy should be considered for patients with multiple cutaneous metastases or non-resectable lesions. Schoenlaub et al. [9] studied 200 cases of cancers with cutaneous or subcutaneous metastasis. Of the patients with colorectal primary tumors, median survival was 4.4 months.

Our case is rare because of skin site of metastasis. $\mathrm{Cu}$ taneous metastasis is a rare but important phenomenon. Moreover, the clinicians should pay special attention to all skin nodules, non-healing ulcers, and persistent indurate erythema.

Informed Consent: Informed consent was obtained from the patient's brother because the patient died.

Conflict of Interest: No conflict of interest was declared by the authors.

Financial Disclosure: The authors declared that this study has received no financial support.
Authorship Contributions: Concept - NSS, SA; Design - NSS; Supervision - EC; Funding - OK, OAU; Materials - NSS; Data collection and/or processing - SA; Analysis and/or interpretation - NSS; Literature review - FHD; Writing - NSS; Critical review - NSS.

\section{REFERENCES}

1. Siegel RL, Miller KD, Jemal A. Cancer statistics, 2018. CA Cancer J Clin 2018;68:7-30. [CrossRef]

2. Lookingbill DP, Spangler N, Helm KF. Cutaneous metastases in patients with metastatic carcinoma: a retrospective study of 4020 patients. J Am Acad Dermatol 1993;29:228-36. [CrossRef]

3. Gmitter TL, Dhawan SS, Phillips MG, Wiszniak J. Cutaneous metastases of colonic adenocarcinoma. Cutis 1990;46:66-8.

4. Bittencourt MJS, Imbiriba AA, Oliveira OA, Santos JEBD. Cutaneous metastasis of colorectal cancer. An Bras Dermatol 2018;93:884-6.

5. Dehal A, Patel S, Kim S, Shapera E, Hussain F. Cutaneous Metastasis of Rectal Cancer: A Case Report and Literature Review. Perm J 2016;20:74-8. [CrossRef]

6. Rendi MH, Dhar AD. Cutaneous metastasis of rectal adenocarcinoma. Dermatol Nurs 2003;15:131-2.

7. Oh SY, Kim DY, Suh KW. Oncologic outcomes following metastasectomy in colorectal cancer patients developing distant metastases after initial treatment. Ann Surg Treat Res 2015;88:253-9. [CrossRef]

8. Nesseris I, Tsamakis C, Gregoriou S, Ditsos I, Christofidou E, Rigopoulos D. Cutaneous metastasis of colon adenocarcinoma: case report and review of the literature. An Bras Dermatol 2013;88:56-8. [CrossRef]

9. Schoenlaub P, Sarraux A, Grosshans E, Heid E, Cribier B. Survival after cutaneous metastasis: a study of 200 cases. [Article in French]. Ann Dermatol Venereol 2001;128:1310-5. 